\title{
Características fisiológicas do feijoeiro cultivado em solos após fitorremediação do picloram ${ }^{1}$
}

\section{Physiological characteristics of bean grown in soils after phytoremediation of picloram}

\author{
Miguel Henrique Rosa Franco²; Vinícius Teixeira Lemos³; Luciana Monteiro Aguiar ${ }^{4}$; André \\ Cabral França ${ }^{5}$; Evander Alves Ferreira ${ }^{6}$; Daniel Valadão Silva ${ }^{7}$
}

\begin{abstract}
Resumo - A fitorremediação tem sido relatada como técnica promissora para a descontaminação de solos com resíduos de herbicidas. Para herbicidas hormonais, há dificuldade na determinação de resíduos pela técnica do bioensaio em função da variação na resposta em crescimento apresentada pela indicadora. Objetivou-se com esse trabalho avaliar o efeito de subdoses do picloram, em solos fitorremediados com braquiária, nas características fisiológicas do feijoeiro. $\mathrm{O}$ ensaio foi realizado em ambiente protegido no delineamento de blocos ao acaso. Aplicou-se diferentes doses do picloram $\left(0 ; 2 ; 4 ; 8 ; 16\right.$ e $\left.32 \mathrm{~g} \mathrm{ha}^{-1}\right)$, sendo posteriormente cultivado com braquiária por 120 dias. Nesta data retirou-se a braquiária dos vasos e semeou o feijão como planta bioindicadora, sendo depois de 30 dias avaliada as características fisiológicas e a matéria seca do feijoeiro. Mesmo após a remediação por plantas de braquiária, as subdoses do picloram afetaram as características fisiológicas do feijoeiro, principalmente a taxa fotossintética e a eficiência no uso da água, sendo essas variáveis as mais indicadas para se avaliar o resíduo do herbicida no solo. A redução dessas variáveis promoveu menor acúmulo de biomassa total das plantas de feijão nos solos fitorremediados. A segunda maior dose do herbicida provocou também redução da relação $\mathrm{F}_{\mathrm{v}} / \mathrm{F}_{\mathrm{m}}$ abaixo de 0,75 , indicando algum tipo de estresse do aparato fotossintético das folhas do feijoeiro.
\end{abstract}

Palavras-chaves: herbicidas auxínicos; fisiologia vegetal; fotossíntese; transpiração

Abstract - Plant remediation has been reported as a promising technique for decontaminating
soil herbicide residues. For hormonal herbicides there is difficulty in determining waste by bioassay
technique due to the variation in growth in response presented by the indicator plant. The objective
of this study was to evaluate the effect of doses of picloram through physiological characteristics
of the bean in phytoremdiation soils with braquiaria. The experiment was arranged in greenhouse
in the design of randomized blocks. Applied increasing doses of picloram $\left(0 ; 2 ; 4 ; 8 ; 16\right.$ e $32 \mathrm{~g} \mathrm{ha}^{-}$
${ }^{1}$ ), subsequently cultivated with Brachiaria for 120 days. In this date the brachiaria was harvested
and sowed beans as bioindicator, 30 days after the emergence of the culture was evaluated the

${ }^{1}$ Recebido para publicação em 25/02/2016 e aprovado em 23/03/2016.

2 Doutorando em Agronomia - UFU, Departamento de Agronomia, Uberlândia - MG.

${ }^{3}$ Doutor em Agronomia - UFLA, Lavras - MG.

${ }^{4}$ Doutoranda em Produção Vegetal - UFVJM, Departamento de Agronomia, Diamantina - MG.

${ }^{5}$ Professor Adjunto - UFVJM, Departamento de Agronomia, Diamantina - MG.

${ }^{6}$ Bolsista PNPD - UFVJM, Departamento de Agronomia, Diamantina - MG.

${ }^{7}$ Professor Adjunto - UFERSA, Departamento de Agronomia, Mossoró - RN. 
physiological characteristics and bean biomass accumulation. Even after remediation by plants Brachiaria, the doses of picloram affected the physiological characteristics of the bean, especially the water use efficiency, these variables are the most appropriate to evaluate the herbicide residues in the soil. The reduction of these variables promoted less accumulation of total biomass of bean plants in soils that was made remediation. The second higher dose of the herbicide also caused reduction of Fv / Fm ratio below 0.75 , indicating some kind of stress photosynthetic apparatus of bean leaves.

Keywords: auxinics herbicides; plant physiology; photosynthesis; transpiration

\section{Introdução}

Os herbicidas são os agrotóxicos com maior volume de aplicação nos sistemas de produção vegetal e considerados a principal ferramenta utilizada no manejo das plantas daninhas devido ao baixo custo, o rendimento operacional e a alta seletividade desses produtos às culturas (SINDAG, 2012).

O picloram é um dos principais herbicidas utilizados em pastagens para o controle de espécies de plantas daninhas de folha larga e apresenta alta seletividade às plantas da família das poaceas. Pertence ao grupo dos herbicidas mimetizadores das auxinas apresentando longo efeito residual no solo (Santos et al., 2006). Essa última característica tem sido relatada como problema para o plantio de culturas sucessoras (carryover) e tem sido objeto de estudos por diversos pesquisadores (Carmo et al., 2008a, b, c; Procópio et al., 2008).

Para atenuar o problema de intoxicação de culturas sensíveis plantadas após a utilização de herbicidas residuais tem sido proposto o plantio de espécies vegetais, com características fitorremediadoras, para descontaminação dos solos (Belo et al., 2007a; Pires et al., 2008; Procópio et al., 2006; Belo et al., 2007b; Santos et al., 2007b). Essa técnica, denominada fitorremediação, é uma alternativa ambientalmente aceita para a despoluição do solo e água contaminados com compostos tóxicos, como herbicidas (Pires et al. 2009).

O sucesso no emprego da fitorremediação depende da natureza química e das propriedades do composto, além da aptidão ecológica da espécie vegetal a ser empregada, a fim de efetivar a remediação e diminuir o tempo de descontaminação da área (Santos et al., 2007a). A condição básica para uma espécie apresentar potencial de fitorremediação, é ser tolerante ao contaminante (Carmo et al., 2008c), sendo uma tarefa difícil na descontaminação de solo contaminado com herbicidas, pois estes são utilizados especificamente no controle de plantas, o que dificulta a seleção de plantas resistentes e fitorremediadoras para estas substancias tóxicas (Coutinho e Barbosa, 2007). Considerando que as características fisiológicas são mais sensíveis ao efeito do herbicida, podese considerar também a avaliação dessas características para determinar o potencial fitorremediador nas plantas usadas como bioindicadoras, sendo o feijoeiro extremamente sensível ao efeito dos herbicidas auxínicos (Santos et al., 2007 a).

Uma das técnicas mais comuns para identificar e quantificar um herbicida no solo ou na água é por meio de bioensaios. Utilizam-se plantas bioindicadoras em que os resíduos do contaminante presente no solo são demonstrados através de alterações nas plantas sensíveis (Monquero et al., 2008). Todavia, a técnica do bioensaio tem sido questionada para aplicação em ambientes com resíduo de herbicidas hormonais. Como esses produtos interferem na síntese de proteínas e enzimas, a variação da concentração na solução do solo produz diferentes efeitos no desenvolvimento da bioindicadora, dificultando a correlação entre aumento de doses e de injúria (Santos et al., 2007). No entanto, são escassos trabalhos que avaliem os efeitos desses herbicidas na atividade fotossintética de espécies bioindicadoras. 
Dessa forma, objetivou-se com esse trabalho avaliar o efeito de subdoses do picloram previamente fitorremediação com braquiária nas características fisiológicas da planta bioindicadora, no caso o feijoeiro.

\section{Material e Métodos}

O experimento foi realizado em casa de vegetação no Departamento de Agronomia da
Universidade Federal dos Vales do Jequitinhonha e Mucuri, no período de novembro de 2012 a março de 2013. Como substrato para o crescimento das plantas, utilizou-se amostras de solo classificado como Argissolo Vermelho-Amarelo, cujas características físicas e químicas estão apresentadas na Tabela 1 .

Tabela 1. Resultados das análises física e química das amostras do Argissolo Vermelho-Amarelo utilizado no experimento. Diamantina - MG, 2012.

\begin{tabular}{|c|c|c|c|c|c|c|c|c|c|c|}
\hline \multicolumn{11}{|c|}{ Análise Física $\left(\text { dag kg }^{-1}\right)^{1}$} \\
\hline Argila & & Silte & \multicolumn{2}{|c|}{ Areia fina } & \multicolumn{6}{|c|}{ Classificação textural } \\
\hline 38 & & 6 & \multicolumn{2}{|c|}{56} & \multicolumn{6}{|c|}{ Franco-argiloso } \\
\hline \multicolumn{11}{|c|}{ Análise Química ${ }^{1}$} \\
\hline $\mathrm{pH}$ & $\mathrm{P}$ & $\mathrm{K}^{+}$ & $\mathrm{H}+\mathrm{Al}$ & $\mathrm{Al}^{3+}$ & $\mathrm{Ca}^{2+}$ & $\mathrm{Mg}^{2+}$ & $\mathrm{CTC}_{\mathrm{pH} 7,0}$ & $\mathrm{~V}$ & $\mathrm{~m}$ & MO \\
\hline $\mathrm{H}_{2} \mathrm{O}$ & \multicolumn{2}{|c|}{$\mathrm{mg} \mathrm{dm}^{-3}$} & \multicolumn{5}{|c|}{$\mathrm{cmol}_{\mathrm{c}} \mathrm{dm}^{-3}$} & \multicolumn{2}{|c|}{$\%$} & $\mathrm{dag} \mathrm{kg}^{-1}$ \\
\hline 6,1 & 0,7 & 25 & 3,7 & 0 & 1,7 & 0,5 & 6 & 38 & 2 & 1 \\
\hline
\end{tabular}

As amostras do solo, coletadas na profundidade de 0-20 cm, em área sem histórico de aplicação de herbicidas, foram secadas ao ar e peneiradas em malha de $5 \mathrm{~mm}$. Para o plantio da espécie remediadora adubou-se o substrato de acordo com o recomendado por Alvarez e Ribeiro (1999) para a Brachiaria brizantha.

Antes do preenchimento dos vasos, revestiram-se cada um deles com filme de polietileno visando evitar perda do herbicida por lixiviação. Após o preenchimento dos vasos com 10,0 kg do substrato, estes foram irrigados ajustando-se a umidade em valor próximo a $80 \%$ da capacidade de campo, fazendo-se a seguir a aplicação do herbicida com um pulverizador de precisão, nas doses especificadas. $\mathrm{O}$ solo foi submetido à subdoses crescentes de picloram $\left(0 ; 2 ; 4 ; 8 ; 16\right.$ e $32 \mathrm{~g} \mathrm{ha}^{-}$ $\left.{ }^{1}\right)$, produto comercial Tordon $^{\circledR}$, sendo posteriormente cultivado com a Brachiaria brizantha (sendo semeadas cinco sementes por vaso com posterior desbaste deixando-se duas plantas por vaso). Após 120 dias da emergência cortou-se a braquiária, sendo que, posteriormente, foi plantado o feijoeiro como planta bioindicadora (duas plantas por vaso). $\mathrm{O}$ ensaio foi montado em blocos ao acaso (DBC) com quatro repetições.

Aos 30 dias após a emergência do feijoeiro foram realizadas as avaliações na folha mais jovem com limbo foliar totalmente expandido, utilizando-se analisador de gases no infravermelho (IRGA), marca ADC, modelo LCA PRO (Analytical Development Co. Ltd, Hoddesdon, UK), em casa de vegetação aberta, permitindo livre circulação do ar. Nessa ocasião, foram determinadas: consumo de $\mathrm{CO}_{2}$ $\left(\Delta \mathrm{C}-\mu \mathrm{mol} \mathrm{mol}{ }^{-1}\right)$, carbono interno $(\mathrm{Ci}-\mu \mathrm{mol}$ $\left.\mathrm{mol}^{-1}\right)$, condutância estomática de vapores de água $\left(\mathrm{Gs}-\mathrm{mol} \mathrm{m}^{-1} \mathrm{~s}^{-1}\right)$, pressão de vapor na câmara subestomática, taxa de transpiração $(\mathrm{E}-$ mol $\left.\mathrm{H}_{2} \mathrm{O} \mathrm{m} \mathrm{m}^{-2} \mathrm{~s}^{-1}\right)$, taxa fotossintética $(A-\mu \mathrm{mol}$ $\left.\mathrm{m}^{-2} \mathrm{~s}^{-1}\right)$, temperatura da folha $\left(\mathrm{T}-{ }^{\circ} \mathrm{C}\right)$, relação carbono interno/carbono atmosférico $(\mathrm{Ci} / \mathrm{Ca})$, sendo calculada ainda a eficiência do uso da água (EUA - mol CO $\mathrm{CO}_{2} \mathrm{~mol} \mathrm{H}_{2} \mathrm{O}^{-1}$ ) pela relação entre quantidade de $\mathrm{CO}_{2}$ fixado pela fotossíntese e quantidade de água transpirada. As avaliações foram realizadas entre 7 e 9 horas da manhã, em dia de céu limpo, com temperatura em média de $25^{\circ} \mathrm{C}$ e com iluminação natural, de forma a manter as 
condições ambientais homogêneas durante as avaliações.

$\mathrm{Na}$ mesma data, realizaram-se as análises de fluorescência inicial $\left(\mathrm{F}_{0}\right)$, fluorescência máxima $\left(F_{m}\right)$ e a razão $F_{v} / F_{m}$. As pinças para a medição dessas variáveis foram colocadas no terço médio da folha do feijoeiro, e a medição foi feita após 30 minutos de adaptação ao escuro, com emissão de um pulso de luz saturante de $0,3 \mathrm{~s}$, sob frequência de 0,6 KHz. Nas mesmas folhas, foram retirados três discos de 8,5 $\mathrm{mm}$ de diâmetro, para determinação do teor de pigmentos fotossintéticos, utilizando o método de extração com o solvente orgânico DMSO (Hiscox e Israelstam, 1979). Os discos foliares foram fatiados em pequenos pedaços, postos em tubos tipo "Falcon" e imersos em 3,0 ml de DMSO, os quais foram mantidos no escuro por 48 horas; após este período, realizaram-se as leituras em espectrofotômetro nas absorbâncias de 480, 649 e 665 nm (Wellburn, 1994).

Após essas medições, coletaram-se as plantas de feijoeiro sendo posteriormente colocadas em estufa de circulação forçada de ar por 72 horas até atingir massa constante para serem pesadas em balança de precisão para a obtenção da massa da matéria seca total.

Os dados foram submetidos à análise de variância e foi calculado o desvio padrão em relação à média dos tratamentos. Os resultados foram representados na forma de gráficos e desvios-padrões.

\section{Resultados e Discussão}

A aplicação do picloram reduziu a massa da matéria seca das plantas de feijoeiro, cultivados em solos remediados por braquiária após a aplicação do herbicida, sendo que, a última dose do produto causou a morte das plantas bioindicadoras (Figura 1). Silva et al. (2012) relataram que o cultivo de Eleusine coracana, outra espécie remediadora do picloram, reduziu em até $56 \%$ a meia vida do herbicida quando comparado com solo sem cultivo. No entanto, no presente trabalho isso não suficiente para permitir o cultivo do feijoeiro no solo estudado.

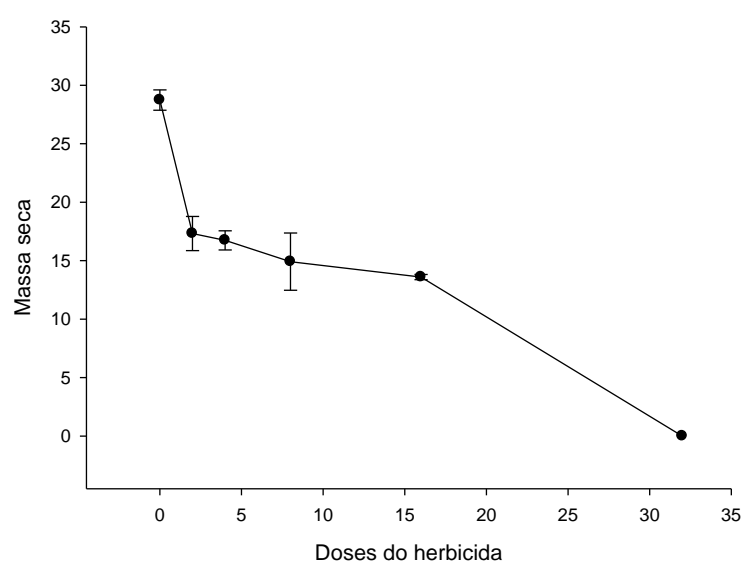

Figura 1. Massa da matéria seca total de plantas de feijoeiro cultivadas em solos contaminados com dose do picloram e fitorremediados por braquiária. Diamantina - MG, 2012.

Nas três primeiras doses do picloram não foi constatada diferença na condutância estomática (Gs) de plantas de feijoeiro cultivadas em solos remediadas por braquiária, no entanto, para as doses 8 e $16 \mathrm{~g} \mathrm{ha}^{-1}$ do herbicida observou tendência de decréscimo da Gs (Figura 2B). A redução da Gs pode ter sido provocada pela ação do picloram, que estimula a produção do etileno nas plantas, o qual por sua vez estimula a síntese do ácido abscísico, que se acumula inicialmente nas folhas e depois é translocado pela planta, atuando no fechamento estomático (Mercier, 2004). Em contrapartida, Barros et al (2014), observaram altos valores de Gs para E. saligna e E. urophyla em solo com picloram e 2,4-D.

Um dos efeitos dos herbicidas auxínicos nas plantas é o acúmulo de cálcio no citoplasma, o estímulo na produção de etileno e a acidificação da parede celular (Belo et al., 2011). O etileno promove a formação de celulase, reduzindo a resistência física da parede celular, ocorrendo elongação da mesma (Machado et al., 2006). Dessa forma, os canais presentes nos feixes vasculares, reduzem a 
translocação de água e fotoassimilados (Belo et al., 2011).

A fotossíntese e, consequentemente, a respiração dependem de fatores, entre eles, o constante fluxo de $\mathrm{CO}_{2}$ e $\mathrm{O}_{2}$ que entra e sai da célula. Esse fluxo livre é função da concentração de $\mathrm{CO}_{2}$ e $\mathrm{O}_{2}$ nos espaços intercelulares dependentes da abertura estomática (Messinger et al., 2006). Esse grupo de herbicidas pode alterar os aspectos fotossintéticos até mesmo de plantas



A

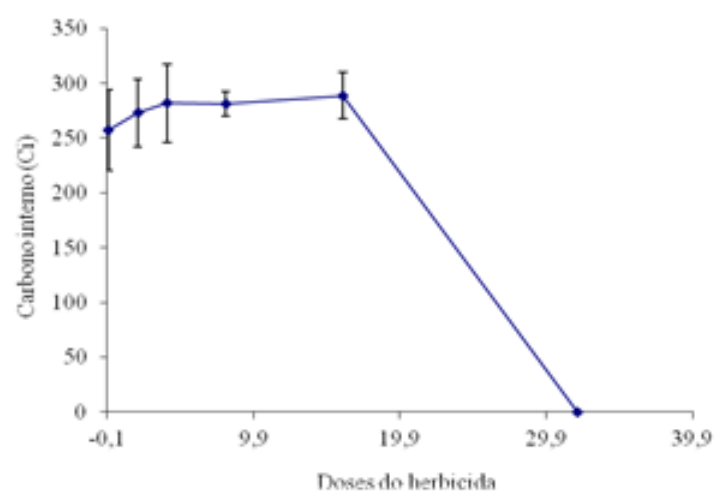

$\mathrm{C}$ consideradas tolerantes (Zhao e Wang, 2010), atuando no fechamento estomático por meio da menor absorção de água pelo sistema radicular (Machado et al., 2006). Com o fechamento dos estômatos, reduz-se a turgescência foliar, o que pode diminuir taxas transpiratórias pela planta. Portanto, qualquer efeito causado pelo picloram que promove a menor absorção ou a translocação de água pode afetar primeiramente a condutância estomática e/ou mesofílica, reduzindo a taxa fotossintética (Belo, 2011).



B

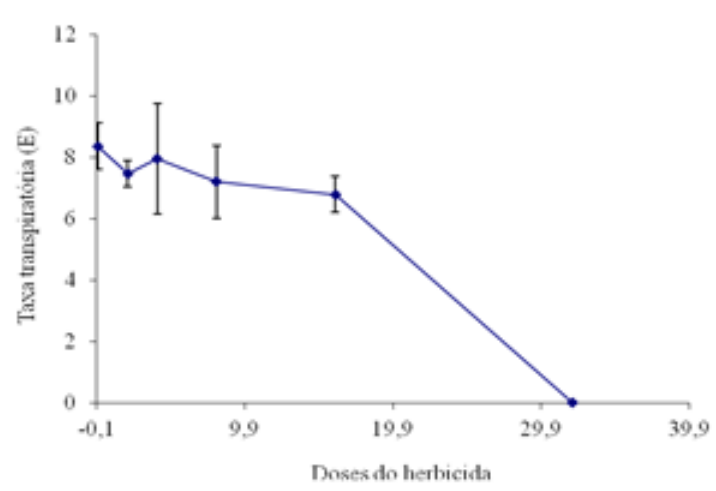

$\mathrm{D}$

Figura 2. A) Taxa fotossintética (A); B) Condutância estomática (Gs); C) Carbono interno (Ci); D) Taxa transpiratória (E) de plantas de feijoeiro cultivadas logo após a braquiária em solo tratados

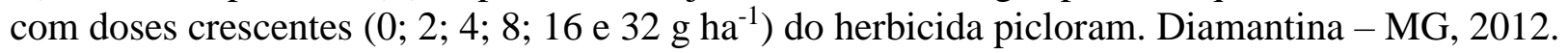

O carbono interno $(\mathrm{Ci})$ e a taxa transpiratória (E) das folhas do feijoeiro foram pouco alterados pela aplicação do picloram (Figura 2C e 2D). No entanto, a dose de $16 \mathrm{~g} \mathrm{ha}^{-}$
${ }^{1}$ do herbicida mostrou-se capaz de reduzir a $\mathrm{E}$ do feijoeiro. $\mathrm{O}$ fechamento estomático influencia na redução da transpiração. A condutância estomática controla a entrada de 
$\mathrm{CO}_{2}$ e saída de água pelo estômato. Se a planta está com uma menor sua abertura, terá uma maior a resistência estomática e, consequentemente, uma menor perda de água por transpiração (Taiz e Zeiger, 2004). Alguns autores trabalhando com herbicidas auxínicos em mostarda, observaram redução de aproximadamente $50 \%$ da taxa fotossintética e da condutância estomática na presença desses produtos (Khan et al., 2002). Wong (2000) também verificou redução de até $80 \%$ da fotossintese de algas quando tratadas com $2 \mathrm{mg}$ $\mathrm{L}^{-1}$ de 2,4-D. Em situações de stress, a planta pode apresentar uma menor produção de produtos da fotossíntese devido à redução de $\mathrm{CO}_{2}$ fixados e menor utilização de energia luminosa (Chaves et al., 2009).

Outro provável mecanismo de limitação da atividade fotossintética pode ser devido à alteração da expressão gênica das plantas com presença de herbicidas, uma vez que o mesmo pode atuar como hormônio, influenciando nos reguladores da expressão gênica, o que pode levar a um bloqueio ou a uma maior expressão de alguns genes. Isso pode modificar a síntese de algumas enzimas essenciais para a fotossíntese (Chapman e Estelle, 2009).

Plantas de feijoeiro cultivadas em solos isentos da aplicação do herbicida picloram apresentaram taxa fotossintética $(A)$ próxima de $16 \mu \mathrm{mol} \mathrm{m} \mathrm{m}^{-2} \mathrm{~s}^{-1}$ (Figura 2A). Entretanto, na primeira dose do herbicida observou-se redução da $A$ para aproximadamente $12 \mu \mathrm{mol} \mathrm{m}{ }^{-2} \mathrm{~s}^{-1}$ e na dose de $16 \mathrm{~g} \mathrm{ha}^{-1}$ esse valor reduziu para cerca de $10 \mu \mathrm{mol} \mathrm{m} \mathrm{m}^{-2} \mathrm{~s}^{-1}$.

A temperatura da folha (T), o $\mathrm{CO} 2$ consumido (DC) e a relação carbono interno/carbono atmosférico $(\mathrm{Ci} / \mathrm{Ca})$ das plantas de feijoeiro não sofreram modificações com o incremento da dose do picloram, com exceção da dose mais alta (Figuras 3A, B e C). Isso indica que, até a dose de $16 \mathrm{~g} \mathrm{ha}^{-1}$, o aparato fotossintético da cultura está funcionando normalmente e que a redução da taxa fotossintética está relacionada com a redução na concentração de $\mathrm{CO}_{2}$ na câmara subestomática, ocasionada pelo fechamento dos estômatos. A relação $\mathrm{Ci} / \mathrm{Ca}$, que faz uma relação direta entre a concentração de $\mathrm{CO}_{2}$ na câmara subestomática e a concentração de $\mathrm{CO}_{2}$ no ambiente, de modo que os decréscimos nos valores de $\mathrm{Ci} / \mathrm{Ca}$ da indicam que as plantas de feijão estão consumindo o $\mathrm{CO}_{2}$ normalmente e que a redução na fotossíntese está ocorrendo em função da redução do substrato para a fotossíntese, ou seja, redução na concentração de $\mathrm{CO}_{2}$ na câmara subestomática.

A eficiência do uso da água (EUA) representa a quantidade de $\mathrm{CO}_{2}$ fixado para a produção de biomassa em função da quantidade de água transpirada. Essa variável relaciona-se com o intervalo de tempo de abertura e fechamento dos estômatos, ao absorver $\mathrm{CO}_{2}$ a planta perde água por transpiração (Concenço et al., 2007). Observaram-se decréscimos nos valores dessa variável com o incremento da dose do produto (Figura 3D). Machado et al. (2010) constataram redução no EUA do eucalipto após a aplicação do glyphosate. Essa redução na eficiência pode ser explicada pela redução na fotossíntese da planta (Figura 2 D) causando em última instância redução no acúmulo de biomassa (Figura 1).

A segunda maior dose do picloram promoveu decréscimo acentuado da fluorescência máxima $\left(\mathrm{F}_{\mathrm{m}}\right)$ diferindo das demais doses (Figura 4A). Um menor $F_{m}$ pode ser atribuída à dissipação não-fotoquímica, especialmente pelo ciclo da xantofila, em que a violaxantina é convertida em zeaxantina (Demmig Adams e Adams, 1992).

$\mathrm{O}$ fenômeno de fluorescência fornece informações sobre os processos fotoquímicos do fotossistema II em plantas. Segundo BolhàrNordenkampf e Oquist (1993), por volta de 95\% dos fótons absorvidos são usados na fotoquímica, quando se há baixa emissão de luz, além disso, 4,5\% são transferidos em calor e $0,5 \%$ é emitido mais uma vez como luz fluorescente. Se todos os centros de reação do fotossistema II estiverem fechados pela interrupção da fotossíntese, $95-97 \%$ da energia pode ser dissipada como calor e $2,5-5,0 \%$, via fluorescência. 


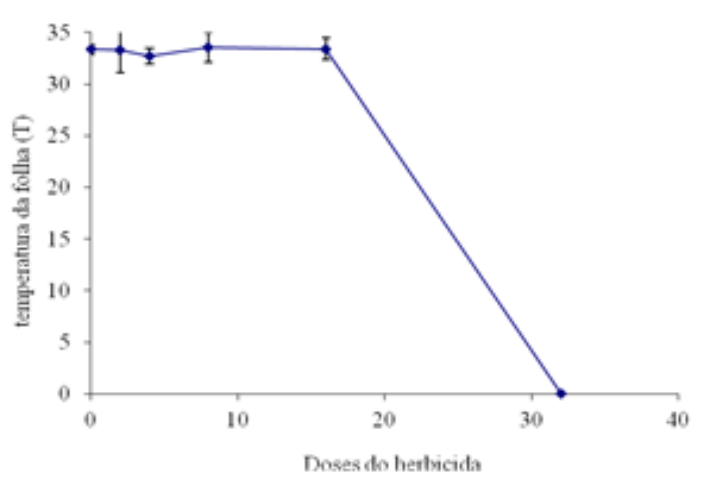

A



$\mathrm{C}$

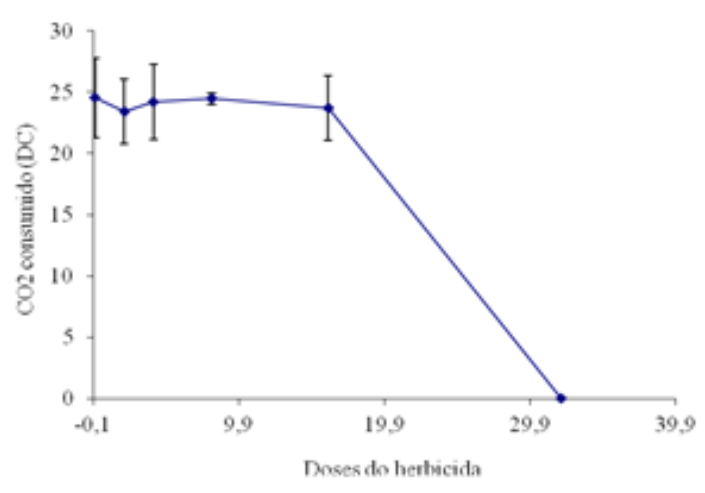

B

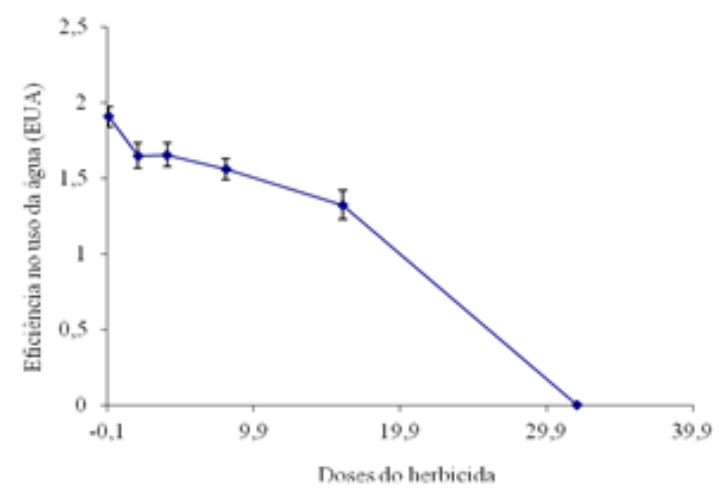

$\mathrm{D}$

Figura 3. A) Temperatura da folha (T); B) CO2 consumido (DC); C) relação Ci/Ca; D) eficiência no uso da água (EUA) de plantas de feijoeiro cultivadas logo após a braquiária em solo tratados com doses crescentes $\left(0 ; 2 ; 4 ; 8 ; 16\right.$ e $\left.32 \mathrm{~g} \mathrm{ha}^{-1}\right)$ do herbicida picloram. Diamantina - MG, 2012.

A eficiência fotossintética máxima das plantas é calculada por $\mathrm{F}_{\mathrm{v}} / \mathrm{F}_{\mathrm{m}}$, em que $\mathrm{F}_{\mathrm{m}}$ é a fluorescência máxima e $F_{v}$ é a fluorescência variável. Já a $F_{0}$ representa a fluorescência inicial, ou seja, a fração da energia absorvida pelo complexo-antena e não transmitida (Rascher et al., 2000).

Segundo Mohanty e Govindjee (1974), por ser rápida, específica e não destrutiva, a análise cinética da fluorescência tem vantagens para estudos do transporte de elétrons durante a fotossíntese. Através de um fluorômetro, é possível registrar o comportamento da fase inicial da fotossíntese, ou seja, o transporte de elétrons no fotossistema II (Baker, 2008).

Mesmo comportamento observado para a $F_{m}$ foi observada para a fluorescência inicial $\left(\mathrm{F}_{0}\right)$ nas folhas da feijoeiro (Figura 4B). Os decréscimos em $\mathrm{F}_{0}$ podem estar envolvidos, danos irreversíveis a subunidades do complexo de evolução do oxigênio, além de efeitos na proteína D1 (Bertamini et al., 2004). Além disso, os valores de $F_{0}$ podem sofrer alterações devido a algum tipo de stress sofrido pela planta, levando a deformação estrutural dos pigmentos no PSII (Baker, 2008).

Para a relação $\mathrm{F}_{\mathrm{v}} / \mathrm{F}_{\mathrm{m}}$ observou-se tendência de decréscimo no valor dessa variável, no entanto, esses valores foram abaixo de 0,75 nas maiores doses do picloram (Figura 3C). Plantas não submetidas a estresses apresentam a variação de 0,75 a 0,85 para a relação $\mathrm{F}_{\mathrm{v}} / \mathrm{F}_{\mathrm{m}}$ (Bòlhar-Nordenkampf et al., 1989), sendo a redução deste, um forte indicador de efeito fotoinibitório quando as plantas estão submetidas à estresses, como o químico (Araus e Hogan, 1994). 

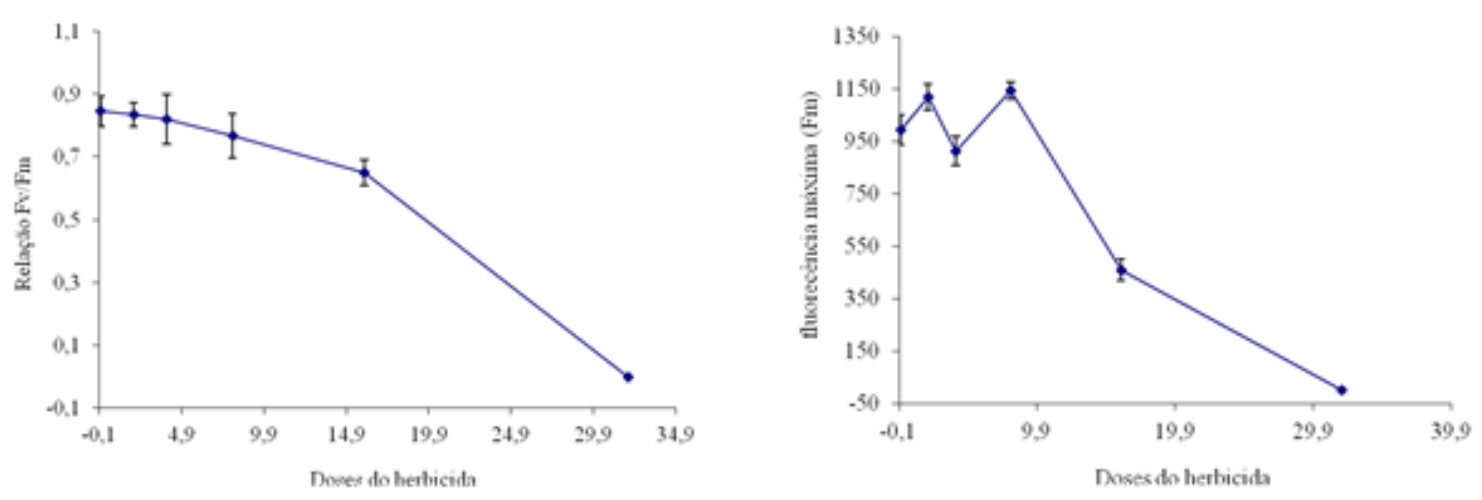

A

B

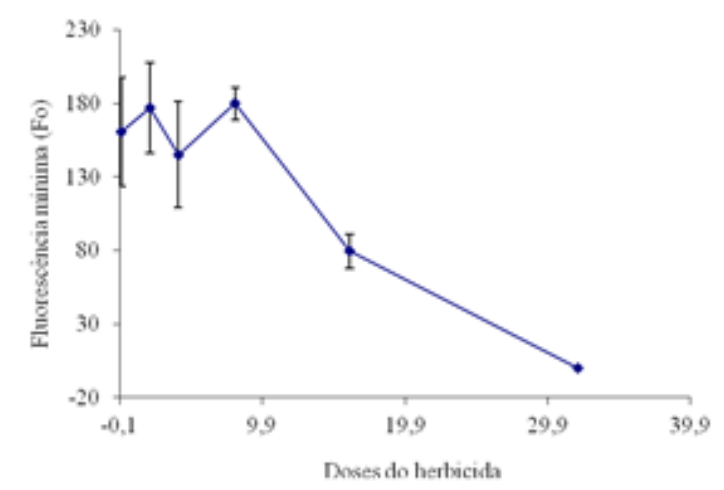

$\mathrm{C}$

Figura 4. A) Fluorescência inicial $\left(F_{0}\right)$; B ) fluorescência máxima $\left(F_{M}\right)$; C) Relação $F_{v} / F_{m}$ de plantas de feijoeiro cultivadas logo após a braquiária em solo tratados com doses crescentes $(0 ; 2 ; 4 ; 8 ; 16$ e $32 \mathrm{~g} \mathrm{ha}^{-1}$ ) do herbicida picloram. Diamantina - MG, 2012.

\section{Conclusões}

De maneira geral, mesmo após a remediação por plantas de braquiária, as subdoses do picloram afetaram as características fisiológicas do feijoeiro, principalmente a $A$ e a EUA, sendo essas variáveis, as mais indicadas para se avaliar o resíduo no solo do herbicida em estudo. A partir de $16 \mathrm{~g} \mathrm{ha}^{-1}$ do herbicida, provocou redução da relação $\mathrm{F}_{\mathrm{v}} / \mathrm{F}_{\mathrm{m}}$, indicando algum tipo de estresse do aparato fotossintético das folhas do feijoeiro. O uso das variáveis fotossintéticas mostrou-se viável para a avaliação da intoxicação de plantas de feijão a resíduos do herbicida picloram.

\section{Agradecimentos}

Os autores agradecem a Coordenação de Aperfeiçoamento de Pessoal de Nível Superior (CAPES) e Fundação de Amparo a Pesquisa do Estado de Minas Gerais (FAPEMIG) pelo apoio financeiro e as bolsas concedidas.

\section{Referências}

Araus, J.L.; Hogan, K.P. Comparative leaf structure and patterns of photoinhibition of the neotropical palms. Scheelea zonensis and Socratea durissima growing in clearing and forest understory during the dry season in Panama. American Journal of Botany, v.81, n.6, p.726-738, 1994. 
Baker, N.R. Chlorophyll fluorescence: a probe of photosynthesis in vivo. Annual Review of Plant Biology, v.59, p.89-113, 2008.

Barros, R.E.; Tuffi Santos L.D.; Cruz L.R; Faria R.M.; Costa C.A.; Felix R.C. Physiological response of eucalyptus species grown in soil treated with Auxin-Mimetic herbicides. Planta Daninha, v.32, n.3, p.629-638, 2014.

Belo, A.F.; Santos, E.A; Santos J.B; Ferreira L.R.; Silva A.A.; Cecon P.R. et al. Efeito da umidade do solo sobre a capacidade de Canavalia ensiformis e Stizolobium aterrimum em remediar solos contaminados com herbicidas. Planta Daninha, v.25, n.2, p.239249, 2007a.

Belo, A.F.; Santos, E.A; Santos J.B; Ferreira L.R.; Silva A.A.; Cecon P.R. et al. Fitorremediação de solo adubado com composto orgânico e contaminado com trifloxysulfuronsodium. Planta Daninha, v.25, n.2, p.251-258, 2007b.

Bertamini, M.; Muthuchelian, K.; Nedunchezhian, N. Photoinhibition of photosynthesis in sun and shade grown leaves of grapevine (Vitis vinifera L.). Photosynthetica, v.42, n.1, p.7-14, 2004.

Bòlhar-Nodenkampf, H.R; Oquist, G.O. Chlorophyll fluorescence as a tool in photosynthesis research. In: Hall, D.O. et al. (Eds.). Photosynthesis and production in a changing environment. London, 1993, p.193206.

Bolhàr-Nordenkampf, H.R.; Long, S.P.; Baker, N.R.; Oquist, G.; Schreiber, U.; Lechner, E.G. Chlorophyll fluorescence as probe of the photosynthetic competence of leaves in the field: a review of current instrument. Functional Ecology, v.3, p.497-514, 1989.

Carmo, M.L.; Procopio, S.O.; Pires, F.R.; Cargnelutti Filho, A.; Braz, G.B.P.; Silva, W.F.P. et al. Influência do período de cultivo de capim-pé-de-galinha-gigante (Eleusine coracana) na fitorremediação de solo contaminado com picloram. Planta Daninha, v.26, n.3, p.601-609, 2008 b.

Carmo, M.L.; Procopio, S.O.; Pires, F.R.; Cargnelutti Filho, A.; Braz, G.B.P.; Silva, W.F.P. et al. Influência do período de cultivo de Panicum maximum (Cultivar Tanzânia) na fitorremediação de solo contaminado com picloram. Planta Daninha, v.26, n.2, p.315322, 2008a.

Carmo, M.L.; Procopio, S.O.; Pires, F.R.; Cargnelutti Filho, A.; Barroso, A.L.L.; Silva, G.P. et al. Seleção de plantas para fitorremediação de solos contaminados com picloram. Planta Daninha, v.26, n.2, p.301313, $2008 \mathrm{c}$.

Chapman, E.J.; Estelle, M. Mechanism of auxinregulated gene expression in plants. Annual Review of Genetics, v.43, n.1, p.265$285,2009$.

Chaves, M.M.; Flexas, J.; Pinheiro, C. Photosynthesis under drought and salt stress: regulation mechanisms from whole plant to cell. Annals of Botany, v.4, n.103, p.551-560, 2009.

Concenço, G.; Ferreira, E.A.; Silva, A.A.; Viana, R.G.; D’Antonino, L.; Vargas, L. et al. Uso da água em biótipos de azevém (Lolium multiflorum) em condição de competição. Planta Daninha, v.25, n.3, p.449-455, 2007.

Coutinho, H.D.; Barbosa, A.R. Fitorremediação: considerações gerais e características de utilização. Silva Lusitana, v.15, n.1, p.103-117, 2007.

Demmig-Adams, B.; Adams, W.W. Photoprotection and other responses of plants to high light stress. Annual Review of Plant Physiology and Plant Molecular Biology, v.43, p.599-626, 1992.

Khan, N.A.; Khan, M.; Ansari, H.R.; Samiullah. Auxin and defoliation effects on photosynthesis and ethylene evolution in mustard. Scientia Horticulturae, v.96, n.1, p.43-51, 2002.

Machado, A.F.L.; Ferreira, L.R.; Santos, L.D.T.; Ferreira, F.A.; Viana, R.G.; Machado, 
M.S. et al. Eficiência fotossintética e uso da água em plantas de eucalipto pulverizadas com glyphosate. Planta Daninha, v.28, n.2, p.319327, 2010.

Machado, R.F.; Barros, A.C.S.A.; Zimmer, P.D.; Amaral, A.S. Reflexos do mecanismo de ação de herbicidas na qualidade fisiológica de sementes e na atividade enzimática em plântulas de arroz. Revista Brasileira de Sementes, v.28, n.3, p.151-160, 2006.

Mercier, H. Auxinas. In: Kerbauy, G.B. (Ed.). Fisiologia vegetal. Rio de Janeiro: Guanabara Koogan, 2004, p.217-249.

Messinger, S.M.; Buckley, T.N.; Mott, K.A. Evidence for involvement of photosynthetic processes in the stomatal response to $\mathrm{CO}_{2}$. Plant Physiology, v.140, n.2, p.771-778, 2006.

Mohanty, P.; Govindjee, S. The slow decline and the subsequent rise of chlorophyll fluorescence transients in intact algal cells. Plant Biochemistry Journals, v.1, n.2, p.78106, 1974.

Monquero, P.A.; Binha D.P.; Amaral, L.R.; Silva P.V.; Silva A.C.; Inacio E.M. Lixiviação de clomazone + ametryn, diuron + hexazinone $\mathrm{e}$ isoxaflutole em dois tipos de solo. Planta Daninha, v.26, n.3, p.685-691, 2008.

Pires, F.R.; Egreja Filho, F.B.; Procópio, S.O. Inferências sobre mineralogia dos solos, sorção e fitorremediação de herbicidas. In: Ferreira, A. et al. (Orgs.). Tópicos especiais em produção vegetal I. Vitória: Edufes, 2009, p.391-406.

Pires, F.R., Santos, J.B.; Souza, C.M.; Dias R.R. Avaliação da fitorremediação de tebuthiuron utilizando Crotalaria juncea como planta indicadora. Revista Ciência Agronômica, v.39, n.2, p.245-250, 2008.

Procópio S.O.; Carmo, M.L.; Pires, F.R.; Cargnelutti Filho, A.; Braz, G.B.P.; Silva, W.F.P. Et al. Fitorremediação de solo contaminado com picloram por capim-pé-degalinha-gigante (Eleusine coracana). Revista
Brasileira de Ciência Solo, v.32, p.2517-2524, 2008.

Rascher, U.; Liebig, M. e Lüttge, U. Evaluation of instant light-responses curves of chlorophyll parameters obtained with a portable chlorophyll fluorometer on site in the field. Plant Cell Environment v.23, n.12, p.1397-1405, 2000.

Santos, E.A.; Santos, J.B.; Ferreira, L.R.; Costa, M.D.; Silva, A.A. Fitoestimulação por Stizolobium aterrimum como processo remediação de solo contaminado com trifloxysulfuron-sodium. Planta Daninha, v.25, n.3, 259-265, 2007.

Santos, J.B.; Silva, A.A.; Procópio, S.O.; Ferreira, L.R. Fitorremediação de áreas contaminadas por herbicidas. In: SILVA, A. A.; SILVA, J. F. (Ed.). Tópicos em manejo de plantas daninhas. Viçosa: UFV, 2007b, p. 249278.

Santos, J.B; Procópio, S.O; Pires, F.R.; Silva, A.A.; Santos, E.A. Fitorremediação de solo contaminado com trifloxysulfuron sodium por diferentes densidades populacionais de feijãode-porco (Canavalia ensiformis (L). DC.). Ciência e Agrotecnologia, v.30, n.3, p.444449, 2006a.

Santos, M.V.; Freitas, F.C.L.; Ferreira, F.A.; Viana, R.G.; Tuffi Santos, L.D.; Fonseca, D.M. Eficácia e persistência no solo de herbicidas utilizados em pastagem. Planta Daninha, v.24, n.2, p.391-398, 2006.

Silva, L.O.C., Silva, A.A, Queiroz, M.E.L.R., Lima, C.F., Rocha, P.R.R.; D'antonino, L. Ação de Eleusine coracana na remediação de solos contaminados com picloram. Planta Daninha, v.30, n.3, p.627-632, 2012.

SINDICATO NACIONAL DA INDÚSTRIA DE PRODUTOS PARA DEFESA AGRÍCOLA -SINDAG. Dados 2009. Disponível em: <http://www.sindag.com.br>. Acesso em: 24 dez. 2012.

Taiz, L.; Zeiger, E. Fisiologia vegetal cap.3, p.719. Porto Alegre: Artmed, 2004. cap.3, p.719 
Wong, P.K. Effects of 2,4-D, glyphosate and paraquat on growth, photosynthesis and chlorophyll-a synthesis of Scenedesmus quadricauda Berb 614. Chemosphere, v.41, p.177-182, 2000.

Zhao, G.W.; Wang, J.H. Effect of auxin on mesocotyl elongation of dark-grown maize under different seeding depths. Russian Journal of Plant Physiology, v.57, n.1, p.79$86,2010$. 